\title{
The presence of Giardia intestinalis in donkeys, Equus asinus, in China
}

\author{
Xiao-Xuan Zhang ${ }^{1,2}$, Fu-Kai Zhang ${ }^{1}$, Fa-Cai Li ${ }^{1}$, Jun-Ling Hou' ${ }^{1}$, Wen-Bin Zheng ${ }^{1}$, Shuai-Zhi Du ${ }^{3}$, Quan Zhao ${ }^{2}$ \\ and Xing-Quan Zhu ${ }^{1 *}$
}

\begin{abstract}
Background: Giardia intestinalis is one of the most important zoonotic enteric parasites. As no information regarding prevalence and genotype of $G$. intestinalis in donkeys (Equus asinus) in China is available, 181 faecal samples from 48 donkeys from Jilin Province, from 104 from Shandong Province and from 29 from Liaoning Province were examined between May and December 2015.
\end{abstract}

Findings: Twenty-eight (15.47\%) out of 181 donkey samples were tested G. intestinalis-positive by nested amplification of the triosephosphate isomerase (tpi) gene. The prevalence in different regional groups varied from 10.42 to $18.27 \%$. The prevalence in adult and young donkeys was 14.29 and $22.92 \%$, respectively. Otherwise, the prevalence was $11.69 \%$ in summer and $18.27 \%$ in winter. However, no statistically significant differences were found in relation to region or age group. Sequence analysis of the tpi, glutamate dehydrogenase ( $g d h)$ and beta giardin (bg) loci identified 4, 1 and 3 subtypes of assemblage B, respectively. Moreover, four novel multilocus genotypes (MLGs novel-1 to novel-4) were identified in assemblage B.

Conclusions: This first report of G. intestinalis in donkeys in China indicates that further studies of nation-wide molecular epidemiology and geographical distribution of Giardia in donkeys are warranted. Effective strategies should be implemented to control G. intestinalis infection in donkeys, other animals and humans.

Keywords: Giardia intestinalis, Prevalence, Genotyping, Donkey, China

\section{Background}

Giardia intestinalis is the only species of Giardia which is found in human beings [1-4]. It is not only distributed worldwide, but also can infect many vertebrates $[5,6]$. Eight assemblages (A-H) have been identified within $G$. intestinalis [6-8]. Of these, assemblages $\mathrm{C}-\mathrm{H}$ seem to be animal-specific [9], but assemblages $\mathrm{A}$ and $\mathrm{B}$ can infect humans and a wide range of non-human hosts $[6,10]$. Diarrhea is the main symptom of giardiasis [11] and transmission is mainly through ingestion of Giardia cysts in contaminated food or water [12]; approximately $2.8 \times 10^{8}$ cases of human giardiasis are reported world-wide per year, and the majority of them are reported in developing countries [6]. In view of such a serious situation, giardiasis

\footnotetext{
* Correspondence: xingquanzhu1@hotmail.com

'State Key Laboratory of Veterinary Etiological Biology, Key Laboratory of Veterinary Parasitology of Gansu Province, Lanzhou Veterinary Research Institute, Chinese Academy of Agricultural Sciences, Lanzhou, Gansu Province 730046, People's Republic of China

Full list of author information is available at the end of the article
}

has attracted considerable attention around the world. Although G. intestinalis infections have been reported in humans and a variety of animal species [13-16], there is little information in donkeys (Equus asinus).

Giardia intestinalis infection in horses has been reported in many countries around the world including China [17-21]. The donkey belongs to the genus Equus. It is an important edible animal species and used in Chinese traditional medicine, and is closely related to horses. Because they are maintained in a close association with their owners and veterinary personnel, donkeys are the important reservoirs for transmission of pathogens (such as Cryptosporidium hominis and Toxoplasma gondii) to humans and other animals $[22,23]$. To determine whether donkeys are hosts of G. intestinalis, we conducted a study on the prevalence and genotypes of G. intestinalis in donkeys in Jilin, Liaoning and Shandong Provinces, China. 


\section{Methods}

\section{Collection and preparation of faecal samples}

A total of 181 donkey faecal samples (48 from Jilin, 27 from Liaoning and 104 from Shandong) were collected from three provinces, in northeastern and eastern China, between March and December 2015. Each of the fresh faecal samples was collected into sterile gloves separately after its defecation onto the ground, placed into box with ice and transported to the laboratory immediately. Genomic DNA was extracted directly from each faecal sample using the Stool DNA kit (OMEGA, Norcross, Georgia, USA) according to the manufacturer's instructions. Genomic DNA was stored at $-20{ }^{\circ} \mathrm{C}$ until PCR amplification.

\section{PCR amplification}

The prevalence and genotypes of G. intestinalis were determined by the nested PCR amplification of the triosephosphate isomerase (tpi) gene, beta giardin $(b g)$ gene and glutamate dehydrogenase $(g d h)$ genes as described by Zhao et al. [24]. The primers and their annealing temperatures are listed in Table 1. Positive and negative controls were included in each amplification. Amplification products were observed under UV light after electrophoresis in 1.5\% agarose gels containing GoldView ${ }^{\mathrm{ma}}$ (Solarbio, Beijing, China).

\section{Sequence and phylogenetic analyses}

Positive secondary PCR products were sequenced by Genscript Company (Nanjing, China). Bidirectional sequencing was used to confirm the accuracy of the sequences. Sequences with mutations were considered as novel genotypes when confirmed from independent two PCR reactions on the same sample. To identify the assemblages and subtypes, nucleotide sequences were aligned with known reference $t p i, g d h$ and $b g$ gene sequences of G. intestinalis available in GenBank using the BLAST (http://www.ncbi.nlm.nih.gov/ BLAST/) and computer program Clustal X 1.83.

\section{Statistical analysis}

The relationship between prevalence of G. intestinalis-infected donkeys and different variables including age, geographic origin and seasons were analyzed by Chi-square test using SPSS version 17.0 (SPSS Inc., Chicago, IL, USA) [25]. The results were considered significant statistically if $P<0.05$. Odds ratios (ORs) and their 95\% confidence intervals $(\mathrm{CI})$ are also given.

\section{Results and discussion}

In this study, a total of 28 (15.47\%, 95\% CI: 10.20-20.74) out of 181 donkey samples were PCR-positive for G. intestinalis (Table 2). The prevalence was 22.92\% (95\% CI: $11.03-$ 34.81 ) in young donkeys and $14.29 \%$ (95\% CI: 8.34-20.23) in adults; no significant difference was observed $\left(\chi^{2}=1.90\right.$, $d f=1, P=0.17$ ) (Table 2). The prevalence in summer and winter was $11.69 \%$ (95\% CI: $4.51-18.87)$ and $18.27 \%(95 \%$ CI: $10.84-25.70)$, respectively $\left(\chi^{2}=1.47, d f=1, P=0.23\right)$ (Table 2). Donkeys from Jilin Province (5/48, 10.42\%, 95\% CI: 1.78-19.06) had a lower prevalence than those from Shandong Province (19/104, 18.27\%, 95\% CI: 10.84-25.70) and Liaoning Province (4/29, 13.79\%, 95\% CI: 1.24-26.34); however, these differences were not significant $\left(\chi^{2}=1.62\right.$, $d f=2, P=0.44$ ) (Table 2). Moreover, $G$. intestinalis prevalence in different farms ranged from 6.12 to $29.09 \%$ (Table 3). Sequences analysis of the $t p i, g d h$ and $b g$ loci indicated only assemblage B was found in the present study (Additional file 1: Figure S1).

The overall prevalence of $G$. intestinalis infection in donkeys was $15.47 \%$ (28/181, 95\% CI: 10.20-20.74), which was higher than that in horses in Xinjiang (1.5\%) [17], Brazil (0.5\%) [26], foals in Belgium (14.2\%) [20], Germany (10\%) [20], Greece (11.6\%) [20], the Netherlands (11.4\%) [20] and Italy (8.6\%) [18], but lower than that in horses in Colombia (17.4\%) [19]. Previous studies demonstrated that survival of G. intestinalis is more likely to be affected

Table 1 Primers used in the study, annealing temperatures used in the PCRs and expected sizes of the PCR products

\begin{tabular}{|c|c|c|c|c|c|}
\hline Gene & Primer & Sequence $\left(5^{\prime}-3^{\prime}\right)$ & Annealing temperature $\left({ }^{\circ} \mathrm{C}\right)$ & Fragment length $(b p)$ & Reference \\
\hline \multirow[t]{4}{*}{$\overline{t p i}$} & F1 & AAATIATGCCTGCTCGTCG & 55 & 530 & {$[24]$} \\
\hline & $\mathrm{R} 1$ & CAAACCTTITCCGCAAACC & & & \\
\hline & F2 & CCCTTCATCGGIGGTAACTT & 55 & & \\
\hline & R2 & GTGGCCACCACICCCGTGCC & & & \\
\hline \multirow[t]{4}{*}{$g d h$} & F1 & TTCCGTRTYCAGTACAACTC & 50 & 530 & [24] \\
\hline & $\mathrm{R} 1$ & ACCTCGTTCTGRGTGGCGCA & & & \\
\hline & F2 & ATGACYGAGCTYCAGAGGCACGT & 65 & & \\
\hline & $\mathrm{R} 2$ & GTGGCGCARGGCATGATGCA & & & \\
\hline \multirow[t]{4}{*}{$b g$} & F1 & AAGCCCGACGACCTCACCCGCAGTGC & 50 & 511 & [24] \\
\hline & $\mathrm{R} 1$ & GAGGCCGCCCTGGATCTTCGAGACGAC & & & \\
\hline & F2 & GAACGAACGAGATCGAGGTCCG & 60 & & \\
\hline & R2 & CTCGACGAGCTTCGTGTT & & & \\
\hline
\end{tabular}


Table 2 Factors associated with prevalence of Giardia intestinalis in donkeys in northern China

\begin{tabular}{lllllll}
\hline Factor & Category & No. tested & No. positive & $\%(95 \% \mathrm{Cl})$ & $P$-value & OR (95\% Cl) \\
\hline Region & Jilin Province & 48 & 5 & $10.42(1.78-19.06)$ & 0.44 & Reference \\
& Liaoning Province & 29 & 4 & $13.79(1.24-26.34)$ & $1.38(0.34-5.60)$ \\
& Shandong Province & 104 & 19 & $18.27(10.84-25.70)$ & $1.92(0.67-5.50)$ \\
Age & Adult & 133 & 19 & $14.29(8.34-20.23)$ & 0.17 & Reference \\
& Young & 48 & 9 & $22.92(11.03-34.81)$ & $1.33(0.58-3.07)$ \\
Season & Summer & 77 & 19 & $11.69(4.51-18.87)$ & 0.23 & Reference \\
& Winter & 104 & 28 & $18.27(10.84-25.70)$ & $1.69(0.72-3.97)$ \\
Total & & 181 & & & & \\
\hline
\end{tabular}

by climate (temperature and relative humidity) [6, 27], so the difference in G. intestinalis prevalence in different regions may be due to different local climatic conditions, as well as the detection methods, sampling time and sample sizes. Moreover, probably because of the smaller sample sizes, seasonal and age-related correlates previously found in cattle [6] and horses [20] were not found in this study.

Assemblages A and B, responsible for the vast majority of human giardiasis $[6,28]$, and assemblage $\mathrm{E}$, a common assemblage of G. intestinalis in cattle [9], have also been reported in horses [20]. However, perhaps due to the smaller sample sizes, only assemblage B was identified in donkeys in the present study. Assemblage B has a broad host range worldwide [20, 28]. In China, isolates of assemblage B have also been found in non-human primates [2], rabbits [3], horses [17], cattle [29], golden takins (Budorcas taxicolor bedfordi) [24], pet chinchillas (Chinchilla lanigera) [30], captive wildlife [13], sheep [31] and goats [31], suggesting interspecies transmission of $G$. intestinalis may be commonly occurring in China, and we should pay enough attention to. More importantly, assemblage B was also identified in raw urban wastewater in northern China [32]. Therefore, our results also suggest that donkeys could be a source of giardiasis outbreaks.

Mixed infections of G. intestinalis genotypes have been recorded from a wide range of hosts worldwide [29, 33]. In cases of co-infections, some assemblages may be detected preferentially using a single locus primers [34]; thus PCR amplification of a single locus may not reflect the accurate information to G. intestinalis infection [34, 35]. A multilocus genotype (MLG) method (tpi, gdh and $b g$ loci) has been developed and widely used for detection of G. intestinalis infection $[6,33,34]$. In the present study, $28 \mathrm{G}$. intestinalis-positive samples were also genotyped based on $b g$ and $g d h$ loci. A total of $28 t p i, 22 b g$ and 16 $g d h$ gene sequences were obtained, and analysis of these genes revealed only one assemblage (B); however, high genetic polymorphism was observed at these loci within this assemblage (Table 4), implying high genetic diversity of G. intestinalis in donkeys in the investigation regions. At the tpi locus, seven polymorphic sites were found compared with the GenBank reference sequence AY368169 (Table 4), and four different assemblage B subtypes were identified (Table 4, Additional file 1: Figure S1c). These sequences all represented new subtypes (KU892519KU892522), and showed a 99\% similarity with the reference sequence (accession no. AY368169, from wastewater in USA [36]). Only one subtype was found at the $g d h$ locus (Additional file 1: Figure S1b), and the sequence (KU892523) had 99\% similarity with the reference sequence available in GenBank with accession number of KR048463 (from a takin in China [24]). Moreover, a total of five SNPs were observed at the $b g$ locus (Table 4), and these sequences (KU892516-KU892518) represented three subtypes (Additional file 1: Figure S1a). Moreover, these subtypes were closely clustered with sub-assemblage BIV (Additional file 1: Figure S1), suggesting that subassemblage BIV was the most common subtype in donkeys

Table 3 Giardia intestinalis genotypes identified in donkeys in different farms

\begin{tabular}{lllll}
\hline Region & Farm ID & Age category $(n)$ & No. positive/No. tested (\%) & Genotype $(n)$ \\
\hline Jilin Province & Farm 1 & Young (10); Adult (38) & 5/48 (10.42) & BIV-1 $(n=2) ;$ BIV-novel-2 $(n=2) ;$ BIV-novel-3 $(n=1)$ \\
Liaoning Province & Farm 2 & Young (6); Adult (23) & $4 / 29(13.79)$ & BIV-1 $(n=2) ;$ BIV-novel-3 $(n=1) ;$ BIV-novel-4 ( $n=1)$ \\
Shandong Province & Farm 3 & Young (14); Adult (35) & $3 / 49(6.12)$ & BIV-1 $(n=1) ;$ BIV-novel-4 $(n=2)$ \\
& Farm 4 & Young (18); Adult (37) & 16/55 (29.09) & BIV-1 $(n=12) ;$ BIV-novel-3 $(n=4)$ \\
& & Young (48); Adult (133) & 28/181 (15.47) & BIV-1 $(n=17) ;$ BIV-novel-2 $(n=2) ;$ BIV-novel-3 (n=6); \\
Total & & & BIV-novel-4 $(n=3)$ \\
\hline
\end{tabular}


Table 4 Variations in tpi, gdh and bg nucleotide sequences among the subtypes of Giardia intestinalis assemblage B

\begin{tabular}{|c|c|c|c|c|c|c|c|c|c|}
\hline \multirow{2}{*}{$\frac{\text { Locus }}{\text { tpi }}$} & \multirow[t]{2}{*}{ Subtype $(n)$} & \multicolumn{7}{|c|}{ Nucleotide at position } & \multirow[t]{2}{*}{ GenBank ID } \\
\hline & & 10 & 11 & 16 & 182 & 197 & 384 & 525 & \\
\hline & Ref. sequence & C & G & - & G & A & G & G & AY368169 \\
\hline & $\mathrm{BIV}-1^{\mathrm{a}}(n=17)$ & C & G & - & A & G & A & G & KU892520 \\
\hline & BIV-novel-2 $(n=2)$ & $\mathrm{T}$ & C & G & A & G & A & G & KU892519 \\
\hline & BIV-novel-3 $(n=6)$ & $\mathrm{T}$ & C & - & A & G & A & G & KU892521 \\
\hline & BIV-novel-4 $(n=3)$ & $\mathrm{T}$ & G & - & A & G & A & $\mathrm{T}$ & KU892522 \\
\hline \multirow[t]{3}{*}{ gdh } & & 219 & & & & & & & \\
\hline & Reference sequence & G & & & & & & & KR048463 \\
\hline & BIV-novel-1 $(n=16)$ & C & & & & & & & KU892523 \\
\hline \multirow[t]{5}{*}{$b g$} & & 14 & 179 & 248 & 446 & 447 & & & \\
\hline & Reference sequence & G & C & C & A & G & & & KM926514 \\
\hline & $\mathrm{BIV}-1^{\mathrm{b}}(n=12)$ & G & C & C & G & A & & & KU892517 \\
\hline & $\mathrm{BIV}-2^{\mathrm{b}}(n=4)$ & G & $\mathrm{T}$ & C & G & A & & & KU892518 \\
\hline & $\mathrm{Bb}-7^{c}(n=6)$ & A & C & $\mathrm{T}$ & G & $A$ & & & KU892516 \\
\hline
\end{tabular}

Identified by Qi et al. [17]

${ }^{b}$ Identified by Coronato Nunes et al. [37]

'Identified by Karim et al. [2]

in the investigated regions. Furthermore, phylogenetic analysis of these isolates showed that these isolates exhibit close relationship with isolates from horses, humans and chinchillas, suggesting that transmission of G. intestinalis may be occurring among these hosts.

Furthermore, 10 out of 28 positive isolates were successfully amplified at all three loci. These samples provided four novel MLGs in the assemblage $B$, namely MLGs novel-1 to novel-4 (Table 5, Fig. 1). Of these, MLG novel-1 $(n=5)$ was the most prevalent MLG, and responsible for $50 \%$ of all MLGs in the present study. These findings suggest a high genetic diversity of this prevalent genotype in donkeys in China, in agreement with previous conclusions that G. intestinalis isolates of the same assemblage may be grouped into distinct MLGs [6, 24].

Table 5 Multilocus characterization of Giardia intestinalis assemblage B isolates from donkeys at tpi, gdh and bg loci

\begin{tabular}{llll}
\hline Isolate $(n)$ & Genotype & GenBank ID & MLGs \\
\hline L7 (5) & BIV-1, & KU892520, & novel-1 \\
& BIV-novel-1, & KU892523, & \\
& BIV-1 & KU892516 & \\
L13 (1) & BIV-novel-2, & KU892519, & novel-2 \\
& BIV-novel-1, & KU892523, & \\
& BIV-2 & KU892517 & \\
L64 (2) & BIV-novel-3, & KU892521, & novel-3 \\
& BIV-novel-1, & KU892523, & \\
& Bb-7 & KU892518 & \\
L93 (2) & BIV-1, & KU892520, & novel-4 \\
& BIV-novel-1, & KU892523, & \\
& Bb-7 & KU892518 & \\
\hline
\end{tabular}

\section{Conclusions}

The present study demonstrated the occurrence of $G$. intestinalis infection in donkeys in China. Sequences analysis suggested that all the $G$. intestinalis isolates represented assemblage $B$, with four, one and three subtypes of assemblage B at the tpi $g d h$ and $b g$ loci, respectively. Moreover, four novel MLGs (MLGs novel-1 to novel-4) were identified within assemblage $B$. The results of the present study not only improve the information of the distribution of G. intestinalis genotypes in China, but also provide the foundation data for preventing and controlling G. intestinalis infection in donkeys, other animals and humans.

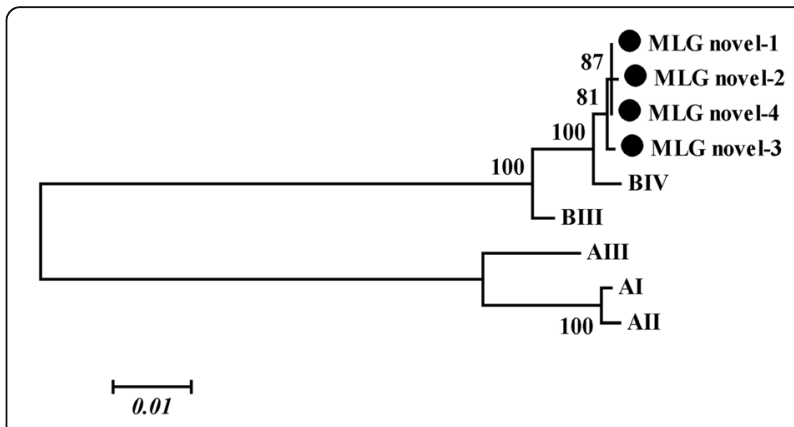

Fig. 1 Phylogenetic relationships of Giardia intestinalis inferred by the neighbour-joining analysis of concatenated $\beta$-giardin, gdh and tpi gene sequences. Multi-locus genotypes from a previous study (Lebbad et al. [38]) are indicated. The bootstrapping was performed using 1000 replicates. Isolates identified in this study are indicated by solid circles 


\section{Additional file}

Additional file 1: Figure S1. Phylogenetic tree of Giardia intestinalis based on nucleotide sequences of the $\beta$-giardin (a), gdh gene (b) and tpi gene $(\mathbf{c})$. Trees were constructed using using the neighbor-joining (NJ) method (Kimura 2-parameter model). Bootstrapping was performed using 1000 replicates. G. intestinalis isolates identified in the present study are indicated by solid circles. (TIF $4193 \mathrm{~kb}$ )

\section{Abbreviations}

bg: Beta giardin gene; Cl: Confidence interval; gdh: Glutamate dehydrogenase gene; MLG: Multilocus genotype; OR: Odds ratio; tpi: Triosephosphate isomerase (tpi) gene

\section{Acknowledgements}

The authors thank the staff and workers in the donkey farms who helped in the collection of faecal samples.

\section{Funding}

This work was supported by the Agricultural Science and Technology Innovation Program (ASTIP) (Grant No. CAAS-ASTIP-2014-LVRI-03).

\section{Availability of data and material}

Representative nucleotide sequences were deposited in GenBank with the following accession numbers: KU892516-KU892518 for the bg gene, and KU892519-KU892522 for the tpi gene, and KU892523 for the gdh gene.

\section{Authors' contributions}

$X Q Z$ and QZ conceived and designed the study, and critically revised the manuscript. XXZ, FKZ and WBZ performed the experiments. XXZ and FKZ analyzed the data. XXZ drafted the manuscript. FCL, JLH and SZD helped in study design, study implementation and manuscript preparation. All authors read and approved the final manuscript.

\section{Competing interests}

The authors declare that they have no competing interests.

\section{Consent for publication}

Not applicable.

\section{Ethics approval}

This study was approved by the Animal Ethics Committee of Lanzhou Veterinary Research Institute, Chinese Academy of Agricultural Sciences (Approval No. LVRIAEC2014-011). Donkeys used for the study were handled in accordance with good animal practices required by the Animal Ethics Procedures and Guidelines of the People's Republic of China.

\section{Author details}

${ }^{1}$ State Key Laboratory of Veterinary Etiological Biology, Key Laboratory of Veterinary Parasitology of Gansu Province, Lanzhou Veterinary Research Institute, Chinese Academy of Agricultural Sciences, Lanzhou, Gansu Province 730046, People's Republic of China. ${ }^{2}$ College of Animal Science and Technology, Jilin Agricultural University, Changchun, Jilin Province 130118, People's Republic of China. ${ }^{3}$ Qilu Animal Health Products Co., Ltd., Jinan, Shandong Province 250100, People's Republic of China.

Received: 26 August 2016 Accepted: 13 December 2016 Published online: 03 January 2017

\section{References}

1. Minetti C, Lamden K, Durband C, Cheesbrough J, Fox A, Wastling JM. Determination of Giardia duodenalis assemblages and multi-locus genotypes in patients with sporadic giardiasis from England. Parasit Vectors. 2015:8:444.

2. Karim MR, Wang R, Yu F, Li T, Dong H, Li D, et al. Multi-locus analysis of Giardia duodenalis from nonhuman primates kept in zoos in China: geographical segregation and host-adaptation of assemblage $B$ isolates. Infect Genet Evol. 2015;30:82-8.
3. Qi M, Xi J, Li J, Wang H, Ning C, Zhang L. Prevalence of zoonotic Giardia duodenalis assemblage $B$ and first identification of assemblage $E$ in rabbit fecal samples isolates from Central China. J Eukaryot Microbiol. 2015;62:810-4.

4. De Liberato C, Berrilli F, Marangi M, Santoro M, Trogu T, Putignani L, et al. Giardia duodenalis in Alpine (Rupicapra rupicapra rupicapra) and Apennine (Rupicapra pyrenaica ornata) chamois. Parasit Vectors. 2015;8:650.

5. Feng Y, Xiao L. Zoonotic potential and molecular epidemiology of Giardia species and giardiasis. Clin Microbiol Rev. 2011;24:110-40.

6. Zhang XX, Tan QD, Zhao GH, Ma JG, Zheng WB, Ni XT, et al. Prevalence, risk factors and multilocus genotyping of Giardia intestinalis in dairy cattle, northwest China. J Eukaryot Microbiol. 2016;63:498-504.

7. Ramírez JD, Heredia RD, Hernández C, León CM, Moncada LI, Reyes P, et al. Molecular diagnosis and genotype analysis of Giardia duodenalis in asymptomatic children from a rural area in central Colombia. Infect Genet Evol. 2015:32:208-13.

8. Santin M, Fayer R. Enterocytozoon bieneusi, Giardia, and Cryptosporidium infecting white-tailed deer. J Eukaryot Microbiol. 2015:62:34-43.

9. Sprong H, Cacciò SM, van der Giessen JW, ZOOPNET network and partners. Identification of zoonotic genotypes of Giardia duodenalis. PLoS Negl Trop Dis. 2009;3, e558.

10. Mohamed AS, Levine M, Camp JW, Jr Lund E, Yoder JS, Glickman LT, et al. Temporal patterns of human and canine Giardia infection in the United States: 2003-2009. Prev Vet Med. 2014;113:249-56.

11. Shin JC, Reyes AW, Kim SH, Kim S, Park HJ, Seo KW, et al. Molecular detection of Giardia intestinalis from stray dogs in animal shelters of Gyeongsangbuk-do (Province) and Daejeon, Korea. Korean J Parasitol. 2015; 53:477-81.

12. Karanis $\mathrm{P}$, Kourenti $\mathrm{C}$, Smith $\mathrm{H}$. Waterborne transmission of protozoan parasites: a worldwide review of outbreaks and lessons learnt. J Water Health. 2007:5:1-38.

13. Li J, Qi M, Chang Y, Wang R, Li T, Dong H, et al. Molecular characterization of Cryptosporidium spp., Giardia duodenalis, and Enterocytozoon bieneusi in captive wildlife at Zhengzhou Zoo, China. J Eukaryot Microbiol. 2015;62:833-9.

14. Ehsan AM, Geurden T, Casaert S, Parvin SM, Islam TM, Ahmed UM, et al. Assessment of zoonotic transmission of Giardia and Cryptosporidium between cattle and humans in rural villages in Bangladesh. PLoS One. 2015; 10, e0118239.

15. Cacciò SM, Ryan U. Molecular epidemiology of giardiasis. Mol Biochem Parasitol. 2008;160:75-80.

16. Bouzid M, Halai K, Jeffreys D, Hunter PR. The prevalence of Giardia infection in dogs and cats, a systematic review and meta-analysis of prevalence studies from stool samples. Vet Parasitol. 2015;207:181-202.

17. Qi M, Zhou H, Wang H, Wang R, Xiao L, Arrowood MJ, et al. Molecular identification of Cryptosporidium spp. and Giardia duodenalis in grazing horses from Xinjiang, China. Vet Parasitol. 2015;209:169-72.

18. Traversa D, Otranto D, Milillo P, Latrofa MS, Giangaspero A, Di Cesare A, et al. Giardia duodenalis sub-assemblage of animal and human origin in horses. Infect Genet Evol. 2012;12:1642-6.

19. Santín M, Cortés Vecino JA, Fayer R. A large scale molecular study of Giardia duodenalis in horses from Colombia. Vet Parasitol. 2013;196:31-6.

20. Kostopoulou D, Casaert S, Tzanidakis N, van Doorn D, Demeler J, von Samson-Himmelstjerna G, et al. The occurrence and genetic characterization of Cryptosporidium and Giardia species in foals in Belgium, the Netherlands, Germany and Greece. Vet Parasitol. 2015;211:170-4.

21. Veronesi F, Passamonti F, Cacciò S, Diaferia M, Piergili FD. Epidemiological survey on equine Cryptosporidium and Giardia infections in Italy and molecular characterization of isolates. Zoonoses Public Health. 2010:57:510-7.

22. Jian F, Liu A, Wang R, Zhang S, Qi M, Zhao W, et al. Common occurrence of Cnyptosporidium hominis in horses and donkeys. Infect Genet Evol. 2016:43:261-6.

23. Alvarado-Esquivel C, Alvarado-Esquivel D, Dubey JP. Prevalence of Toxoplasma gondii antibodies in domestic donkeys (Equus asinus) in Durango, Mexico slaughtered for human consumption. BMC Vet Res. 2015;11:6.

24. Zhao GH, Du SZ, Wang HB, Hu XF, Deng MJ, Yu SK, et al. First report of zoonotic Cryptosporidium spp., Giardia intestinalis and Enterocytozoon bieneusi in golden takins (Budorcas taxicolor bedfordi). Infect Genet Evol. 2015;34:394-401.

25. $X u$ H, Jin Y, Wu W, Li P, Wang L, Li N, et al. Genotypes of Cryptosporidium spp., Enterocytozoon bieneusi and Giardia duodenalis in dogs and cats in Shanghai, China. Parasit Vectors. 2016:9:121.

26. De Souza PN, Bomfim TC, Huber F, Abboud LC, Gomes RS. Natural infection by Cryptosporidium sp., Giardia sp. and Eimeria leuckarti in three groups of equines with different handlings in Rio de Janeiro, Brazil. Vet Parasitol. 2009;160:327-33. 
27. Alum A, Absar IM, Asaad H, Rubino JR, ljaz MK. Impact of environmental conditions on the survival of Cryptosporidium and Giardia on environmental surfaces. Interdiscip Perspect Infect Dis. 2014;2014:210385.

28. Ballweber LR, Xiao L, Bowman DD, Kahn G, Cama VA. Giardiasis in dogs and cats: update on epidemiology and public health significance. Trends Parasitol. 2010;26:180-9.

29. Huang J, Yue D, Qi M, Wang R, Zhao J, Li J, et al. Prevalence and molecular characterization of Cryptosporidium spp. and Giardia duodenalis in dairy cattle in Ningxia, northwestern China. BMC Vet Res. 2014;10:292.

30. Qi M, Yu F, Li S, Wang H, Luo N, Huang J, et al. Multilocus genotyping of potentially zoonotic Giardia duodenalis in pet chinchillas (Chinchilla lanigera) in China. Vet Parasitol. 2015;208:113-7.

31. Zhang W, Zhang X, Wang R, Liu A, Shen Y, Ling H, et al. Genetic characterizations of Giardia duodenalis in sheep and goats in Heilongjiang Province, China and possibility of zoonotic transmission. PLoS Negl Trop Dis. 2012;6, e1826

32. Liu A, Ji H, Wang E, Liu J, Xiao L, Shen Y, et al. Molecular identification and distribution of Cryptosporidium and Giardia duodenalis in raw urban wastewater in Harbin. China Parasitol Res. 2011;109:913-8.

33. Ankarklev J, Hestvik E, Lebbad M, Lindh J, Kaddu-Mulindwa DH, Andersson JO, et al. Common coinfections of Giardia intestinalis and Helicobacter pylori in non-symptomatic Ugandan children. PLoS Negl Trop Dis. 2012;6, e1780.

34. Cacciò SM, Beck R, Lalle M, Marinculic A, Pozio E. Multilocus genotyping of Giardia duodenalis reveals striking differences between assemblages A and B. Int J Parasitol. 2008;38:1523-31.

35. Wielinga CM, Thompson RC. Comparative evaluation of Giardia duodenalis sequence data. Parasitology. 2007;134:1795-821.

36. Sulaiman IM, Jiang J, Singh A, Xiao L. Distribution of Giardia duodenalis genotypes and subgenotypes in raw urban wastewater in Milwaukee, Wisconsin. Appl Environ Microbiol. 2004;70:3776-80.

37. Coronato Nunes B, Pavan MG, Jaeger LH, Monteiro K, Xavier SC, Monteiro FA, et al. Spatial and molecular epidemiology of Giardia intestinalis deep in the Amazon, Brazil. PLoS One. 2016;11, e0158805.

38. Lebbad M, Mattsson JG, Christensson B, Ljungström B, Backhans A, Andersson JO, et al. From mouse to moose: multilocus genotyping of Giardia isolates from various animal species. Vet Parasitol. 2010;168:231-9.

\section{Submit your next manuscript to BioMed Central and we will help you at every step:}

- We accept pre-submission inquiries

- Our selector tool helps you to find the most relevant journal

- We provide round the clock customer support

- Convenient online submission

- Thorough peer review

- Inclusion in PubMed and all major indexing services

- Maximum visibility for your research

Submit your manuscript at www biomedcentral.com/submit

) Biomed Central 